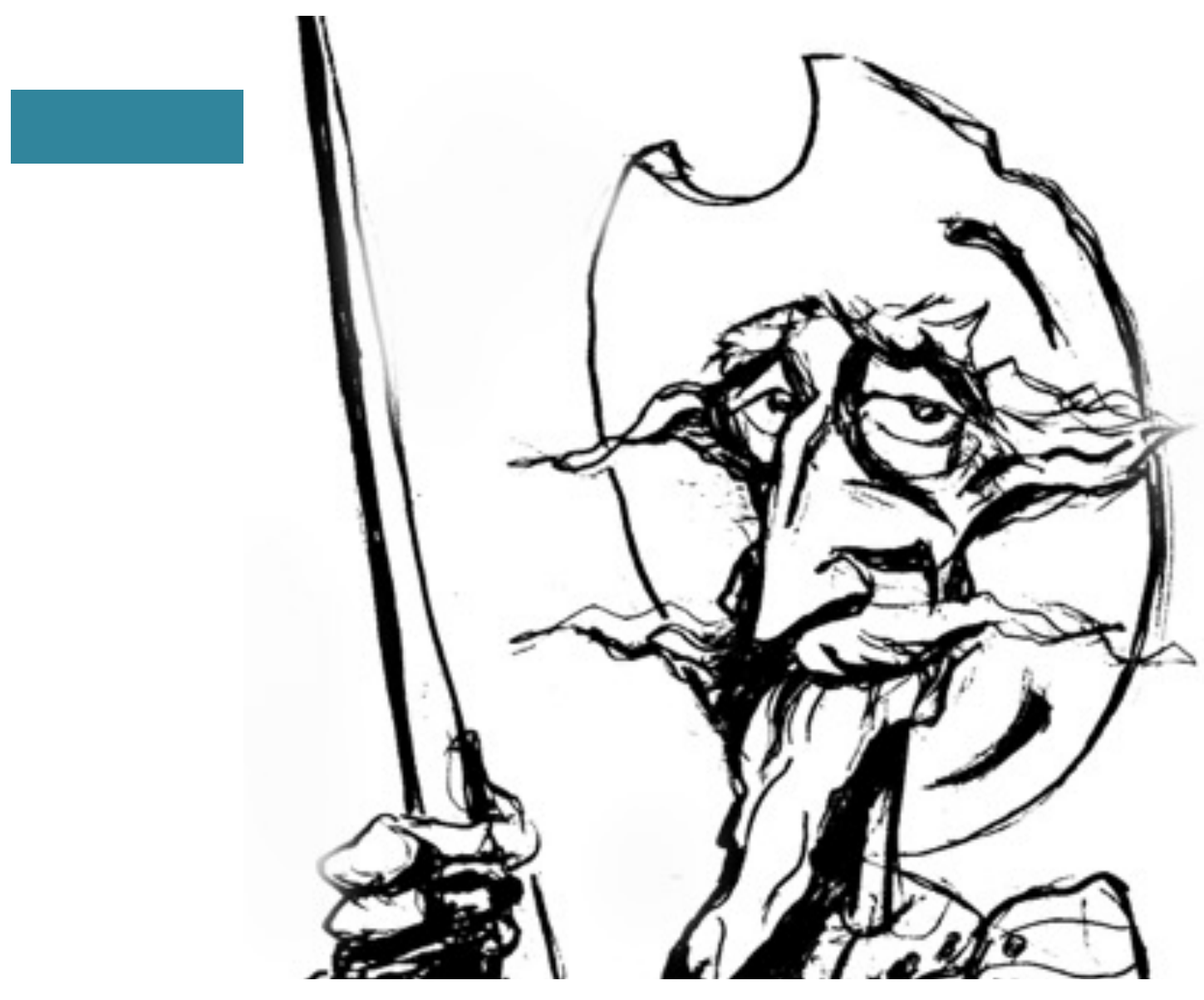

Desertores y rebeldes. Dos formas de entender la militarización en Guatemala y Chiapas, 1825-1859

[Juan Carlos Sarazúa Pérez] 


\title{
Desertores y rebeldes. Dos formas de entender la militarización en Guatemala y Chiapas, 1825-1859
}

\author{
Deserters and rebels. Two ways to understand the militarization in \\ Guatemala and Chiapas, 1825-1859
}

\author{
JuAN CARLOS SARAZÚA PÉREZ
}

\section{Resumen}

La investigación sobre la movilización militar y la aplicación de la justicia durante la primera mitad del siglo XIX ha aportado nuevos matices que ayudan a comprender la construcción estatal de ese periodo en la América Hispana. Este artículo se inspira en esta renovación para hacer un primer intento de exploración acerca de las formas en que los militares y milicianos eran juzgados. Problema de primera importancia porque la nueva legitimidad política pasaba por la ciudadanía, y esta era entendida en muchas ocasiones como un derecho ganado por la participación en las milicias y unidades regulares. Se abordarán dos espacios territoriales en construcción, Guatemala y Chiapas, que fueron parte de la Capitanía General de Guatemala y que mantuvieron vínculos políticos y económicos a pesar de ser parte de dos proyectos nacionales distintos después de 1823 .

\section{Palabras clave}

Justicia - fuero militar - milicias - acuerdos políticos

\begin{abstract}
Research on military mobilization and the application of justice during the first half of the nineteenth century has provided new nuances that help to understand the state construction of that period in Hispanic America. This article is inspired by this renewal to make a first attempt at exploration about the ways in which the military and militiamen were judged. Problem of first importance because the new political legitimacy passed through the citizenship, and this was understood in many occasions as a right won by the participation in the militias and regular units. This article will address two territorial spaces under construction, Guatemala and Chiapas, which were part of the General Captaincy of Guatemala and maintained political and economic ties despite being part of two different national projects after 1823 .
\end{abstract}

\section{Keywords}

Justice - military jurisdiction - militias - political agreements

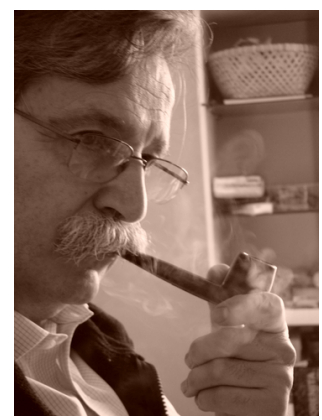

Recibido con pedido de publicación el 15 de septiembre de 2017

Aceptado para su publicación el 25 de noviembre de 2017

Versión definitiva recibida el 20 de diciembre de 2017

Juan Carlos Sarazúa Pérez, Universidad Nacional Autónoma de México, Centro Peninsular en Humanidades y en Ciencias Sociales, México; e-mail: jsarazua2@gmail.com

Esta obra se publica bajo licencia Creative Commons. Atribución-NoComercial-CompartirIgual (cc)) EY-No-sa Internacional

Sarazúa Pérez, Juan Carlos "Desertores y rebeldes. Dos formas de entender la militarización en Guatemala y Chiapas, 1825-1859", Prohistoria, Año XX, núm. 28, Homenaje a Juan Carlos Garavaglia, dic. 2017, pp. 99-122. 


$$
\begin{array}{r}
\text { A la memoria de Juan Carlos Garavaglia, } \\
\text { maestro y amigo, } \\
\text { que siempre compartió su experiencia, } \\
\text { un agudo sentido del humor y, sobre todo, } \\
\text { su pasión por la historia }
\end{array}
$$

\section{Introducción}

Este artículo es un primer avance de una investigación de mayor aliento sobre la justicia y sus implicaciones políticas en Chiapas y Guatemala durante la primera mitad del siglo XIX. Por esta razón, tiene como objetivo central hacer una primera exploración de las formas de juzgar a los militares y rebeldes por parte de las autoridades. A primera vista, pareciera un problema menor, cercano a la disciplina militar, siempre vista como severa y con la capacidad de moldear a los individuos. Sin embargo, si se desplaza el punto de vista, se podría observar un fenómeno que dice mucho acerca de la relación política que estaba en transformación entre pueblos, comunidades y gobierno. ${ }^{1}$ Primero, los militares encarnaban en el imaginario del liberalismo temprano el ciudadano en armas, hombre, que aportaba "sangre" con tal de defender a la república de los enemigos internos y externos. Segundo, a través de su lealtad, los militares construían los vínculos necesarios para darle sentido a la nueva "comunidad política" basada en la relación directa entre ciudadanos y autoridades. Tercero, la relación de lealtad de los ciudadanos en armas con las autoridades era, por estas condiciones, la forma esperada para garantizar la unidad de los nuevos Estados. En este sentido, juzgar a los militares y rebeldes era uno de los mecanismos que tenían las autoridades para evitar el rompimiento del contrato político que sustentaba la nueva legitimidad republicana. Es decir, llevar a cabo estos procesos judiciales era, en un sentido profundo, conservar el consenso político y la supervivencia del proyecto cuestionado. Visto desde otro lado, el de los acusados, en el proceso judicial podían salir a luz las contradicciones y tensiones presentes en los proyectos políticos que se querían instaurar.

En un ensayo que aborda los caminos de la historia andina colonial tardía, Sergio Serulnikov recuerda que la sociedad colonial estaba "intensamente politizada", pues las relaciones sociales y sus conflictos estuvieron regidos por la Corona y sus representantes en América por medio de las instancias judiciales. Sin contar con la separación de las funciones administrativas y judiciales propias del Estado contemporáneo, en la Colonia cualquier procedimiento que involucraba una petición de justicia era en sí mismo un acto político. Esto hizo que los grupos sociales constantemente demandaran en los tribunales la restitución de sus derechos (tierras, honor y protección), apoyados por una parte del cuerpo de notarios y escribanos. Basados en la legitimidad que les daba el derecho y, a su vez, en la tradición y la pluralidad social corporativa, las quejas que estos presentaban en los tribunales eran una forma de recuperar el orden y, para las autoridades, de ejercer el poder. De esta manera:

\footnotetext{
1 Tal como lo afirma Raúl Fradkin. FRADKIN, Raúl “Cultura jurídica y cultura política: la población rural de Buenos Aires en una época de transición (1780-1830)" en FRADKIN, Raúl (Comp.) La ley es tela de araña. Ley, justicia y sociedad rural en Buenos Aires, 1780-1830, Prometeo Libros, Buenos Aires, 2009, pp. 159-186.
} 
"En el imaginario político de la época, toda percibida afrenta a las prerrogativas de los individuos y las corporaciones constituía una afrenta a la santidad de la tradición y a la potestad del monarca pues era de éstos que aquellas prerrogativas en última instancia emanaban. Los conflictos sociales eran por necesidad asuntos de estado. Las disputas sociales, horizontales y verticales, tendían a transmutarse en luchas políticas; y las luchas políticas a traducirse en un flujo ascendente y descendente de apelaciones a la justicia regia." ${ }^{2}$

La perspectiva que aporta Serulnikov recuerda dos hechos fundamentales para pensar las relaciones políticas a través de la justicia: como práctica, la justicia no se limitaba a la actuación de los interesados en los tribunales y los alcances de la cultura política sobre la justicia no se limitaban a las poblaciones criollas y mestizas, pues se daban entre los indígenas. Este hecho es reforzado por la historia social del derecho; esta ha mostrado que una de las bases de la legitimidad de la Monarquía en sus territorios era el papel que la figura del Rey jugaba como repartidor de justicia y, en los lugares donde no podía estar físicamente, sus delegados actuaban como garantes de los privilegios y derechos que tenían los vasallos y habitantes. ${ }^{3}$ En ese sentido, la justicia bajo la Monarquía Hispana no era un campo unificado, porque respondía a privilegios y obligaciones desiguales acordes a los "cuerpos" que formaban el cuerpo político de la nación. En cambio, la transición hacia un proyecto republicano en el siglo XIX implicó la unificación y codificación de las prácticas jurídicas, golpeando de paso los comportamientos corporativos. Las pugnas provocadas por este paso explicarían el largo aliento de las prácticas y bases doctrinarias del derecho colonial durante el XIX, pues fue una forma de continuar negociando los equilibrios políticos por parte de autoridades $y$ grupos.

Para el mundo hispanoamericano, la historiografía que aborda la justicia desde perspectivas culturales y sociales ha crecido en las dos últimas décadas hasta convertirse hoy en un campo fértil para mostrar la acción de los subalternos en distintas facetas. Ya sea en la adopción estratégica del lenguaje político del XIX por parte de comunidades indígenas o en la transformación de las concepciones ciudadanas y su relación con las autoridades; este tipo de trabajos se han constituido en un campo propio de investigación. ${ }^{4}$

Si este papel central de la justicia ha sido recuperado por varios autores, tanto para los niveles más altos de la política en las Monarquías Hispana y Lusitana, como en las consecuencias locales a la hora de cuestionar la legitimidad real, es notable que la reflexión sobre las consecuencias políticas de

\footnotetext{
2 SERULNIKOV, Sergio "Representaciones, prácticas, acontecimientos. Apuntes sobre la historia política andina", en Memoria Americana, XX, núm. 1, enero-junio 2012, p. 91.

${ }^{3}$ Cf. HESPANHA, Antonio Visperas del Leviatán. Instituciones y poder politico (Portugal, siglo XVII), Editorial Taurus, Madrid, 1989; GARRIGA, Carlos “Orden jurídico y poder político en el Antiguo Régimen", Centro de Investigación y Docencia Económicas, Madrid, 2004; MANORI, Luca "Justicia y administración entre Antiguo y Nuevo Régimen", en Revista Jurídica de la Universidad Autónoma de Madrid, XVI, 2007, pp. 125-146.

${ }^{4}$ Para México, GALANATE, Mirian "La historiografía reciente de la justicia en México, siglo XIX: perspectivas, temas y aportes", Revista Complutense de Historia de América, XXXVII, Madrid, 2011, pp. 93-115; para el Río de la Plata, BARRIERA, Darío “Justicias, jueces y culturas jurídicas en el siglo XIX rioplatense" Nuevo Mundo Mundos Nuevos http: / / nuevomundo.revues.org/59252; una perspectiva amplia y abarcadora en CASELLI, Elisa (Coord.) Justicias, agentes y jurisdicciones. De la Monarquía Hispánica a los Estados Nacionales (España y América, siglos XVI-XIX), Fondo de Cultura Económica, Madrid, 2016.
} 
la justicia en el periodo republicano en Centroamérica y en el sureste mexicano no haya ocupado un mayor espacio en la reflexión historiográfica. Esto último no significa que no existan avances. Por el contrario, en los últimos años han salido a luz varios trabajos que se articulan alrededor de esta temática. Sin embargo, hace falta un mayor seguimiento en la esfera de la historia judicial y militar.

\section{Guerra y justicia militar en Guatemala}

A pesar de su diversidad, una parte importante de los estudios sobre las guerras decimonónicas en América Latina parten de un principio fundamental: considerar a estos hechos sociales como expresión de Estados, como una tarea en la que se expresa el tipo de Estado que la lleva a cabo. Sin embargo, la postura aquí tomada es romper las ataduras que establecía el hecho de partir de la concepción estatal como tal, sobre todo el resultado final como una lente para entender el periodo en estudio. En este sentido, las posturas de algunos autores que ven a los Ejércitos como "brazos armados del Estado", en realidad ocultan aspectos centrales de la actividad guerrera. Por el contrario, los enfoques más recientes sobre la guerra están guiados por la intención de recuperar la autonomía de aquellos que combatían, de sus agendas políticas y del proceso cambiante que implicó su participación en las luchas facciosas. ${ }^{5}$

Por estas razones, antes de calificar a las guerras como caudillistas o clientelistas, el reto consiste en indagar en estos procesos políticos que no dependían solo de la concepción de Estado, sino de pugnas locales, de las tensiones étnicas y las cambiantes identificaciones políticas. Es decir, en las intersecciones de los distintos campos temáticos que permitan ver esa agenda compleja que tenían todos los actores involucrados. ${ }^{6}$

Para lograr este objetivo, el trabajo de investigación sobre la guerra ha estado concentrado en dos espacios, el oriente y centro, pues en estos lugares tuvieron lugar los principales reclutamientos para la formación de ejércitos para las guerras con los otros Estados y fueron zonas donde surgieron rebeliones de larga data en contra de las autoridades en Ciudad de Guatemala. Esto se complementa con los trabajos más detallados realizados para la región de Los Altos. ${ }^{7}$ Las diferencias en el servicio militar y sus consecuencias en la lucha de poder estuvieron marcadas por las diferencias regionales.

El objetivo de estudiar cómo la sociedad se prepara y moviliza para la guerra es indagar en las lógicas sociales dinámicas y sus cambios a lo largo del tiempo. De esta forma, usar la guerra como un prisma para ver facetas no siempre visibles de las personas y grupos que participaron requiere que se

\footnotetext{
${ }^{5}$ RABINOVICH, Alejandro "La máquina de guerra y el Estado: el Ejército de los Andes tras la caída del estado central del Río de la Plata en 1820", en GARAVAGLIA, Juan Carlos - PRO RUIZ, Juan - ZIMMERMANN, Eduardo Las fuerzas de guerra en la construcción del Estado: América Latina, siglo XIX, Prohistoria, SBLA-UPF, Rosario, 2012, pp. 287-318.

6 Como hace algunos años propuso Sergio Serulnikov para estudiar los actores de las independencias en la América Hispana. SERULNIKOV, Sergio "En torno a los actores, la política y el orden social en la independencia hispanoamericana", Nuevo Mundo Mundos Nuevos [En ligne], Débats, mis en ligne le 18 mai 2010, https:// nuevomundo.revues.org/ 59668 7 GONZÁLEZ ALZATE, Jorge "A history of Los Altos, Guatemala a study of regional conflict and national integration, 1750-1885", Tesis de doctorado, Tulane University, 1995; TARACENA, Arturo Invención criolla, sueño ladino, pesadilla indígena. Los Altos de Guatemala, de región a Estado (1750-1871), CIRMA, Antigua Guatemala, 2000; POLLACK, Aaron Levantamiento $k^{\prime} i c h e^{\prime}$ en Totonicapán, 1820: los lugares de las políticas subalternas, AVANCSO, Guatemala, 2008.
} 
profundice en los impactos de la actividad militar. Si se deja atrás la relación subordinada de la guerra a la institucionalidad estatal, uno de los primeros aspectos a tener en cuenta es el grado de militarización de la sociedad. Es decir, a la impronta que ha tenido en las relaciones sociales la actividad guerrera. Rabinovich hace mención de un indicado básico, el grado de militarización a partir de la relación de soldados inscritos en unidades militares, regulares o irregulares, con respecto a los hombres adultos, no con la población total.

He utilizado este indicador para analizar la profundidad de la militarización en el oriente de Guatemala para 1863, año en el que se disponen cifras. ${ }^{8}$ En algunas poblaciones se reportaron que uno de cada dos hombres adultos (15-50 años) estaba en la columna militar hacia San Salvador. Si se toma en cuenta que estos balances eran tomados en un momento en el que también se habían reportado deserciones, podemos considerar la hipótesis de que en algunos lugares prácticamente todos los hombres adultos formaban parte del Ejército expedicionario. Eso habla en realidad de que la sociedad se había visto moldeada por las dinámicas marciales propias de la guerra, que los lazos de amistad y enemistad, compadrazgo pero también politización pasaban por el ejercicio de las armas. Al mismo tiempo, se confirma a otro nivel las reflexiones que Sullivan Gonzalez hizo con respecto al impacto del discurso nacionalista difundido por la Iglesia Católica durante el periodo de Rafael Carrera (18391865) en la región de oriente y su papel en la formación de los ejércitos guatemaltecos. $^{9}$

El otro aspecto central en el estudio de la guerra decimonónica es la autonomía de los individuos y actores colectivos que se incorporaban a las filas o columnas militares e insurgentes. Esta faceta es fundamental porque implica el reconocimiento como actores a los que formaban parte de las columnas militares, sin negar la existencia propia del clientelismo. Pero no asumiendo que es la única respuesta. La politización se puede ejemplificar en dos aspectos en la Guatemala del siglo XIX. La primera fue la constante movilización de importantes sectores poblacionales como insurgentes en contra de los gobierno de turno. Sin lugar a dudas, la "soberanía de los pueblos" jugó un papel clave en los pronunciamientos contrarios al gobierno, pero también a la politización difundida por la dinámica de militarización.

De aquí se desprenden varios aspectos notables que deben de ser rescatados con más precisión en futuras publicaciones. La primera es relacionada al pago de los soldados. Se debe evitar a toda costa la perspectiva dicotómica entre la movilización por medio de pago (clientelismo) y el soldado voluntario (politización). Como ya lo dijeran para el Río de la Plata, en sociedades donde la moneda circulante era tan escaza, la promesa del pago podía ser parte de las negociaciones entre oficiales y soldados. Segundo, el alto grado de politización para mantener su participación en los conflictos en forma voluntaria y, tercero, el papel de la dinámica política producida de construir un proyecto republicano en Centroamérica y Guatemala.

Otro aspecto que habla del impacto de las guerras en las dinámicas sociales es la de los exiliados y circulaciones entre Estados a la hora de transmitir técnicas militares o compartir líneas políticas semejantes. En la

\footnotetext{
8 SARAZÚA, Juan Carlos "Santa Rosa y Chiquimula, participación militar y fiscalidad", en CONNAUGHTON, Brian (Coord.) Repensando Guatemala en la época de Rafael Carrera. El país, el hombre y las coordenadas de su tiempo, Gedisa Editorial, México, 2015, pp. 209-248.

9 SULLIVAN-GONZÁLEZ, Douglas Piety, power and politics: religion and nation formation in Guatemala, 1821-1871, University of Pitssburg Press, 1998.
} 
historiografía hay varios casos ilustrativos sobre esto. Uno de los más conocidos es el del Oficial Nicolás Raoul, veterano de las guerras napoleónicas que, como muchos otros, buscaron en América el exilio una vez sucedida la derrota en Francia. De igual forma, es conocido el caso de los exiliados de la Nueva Granada que llegaron a tierras centroamericanas durante la Primera Guerra Federal (1826-1829) para aliarse a los liberales salvadoreños. ${ }^{10}$ Aunque en Centroamérica nunca se llegó al nivel del Río de la Plata o México, la presencia de estos "mercenarios" en realidad indica las conexiones políticas existentes entre personas más allá de las fronteras próximas o cercanas. Eran redes que cubrían el Caribe y el Atlántico con una complejidad que hace poco han salido a luz con más detalle.

Me interesa rescatar aquí la intensidad de la politización de los actores, ya sean extranjeros o locales. En este mismo sentido, los exiliados provenientes de Chiapas y Centroamérica que llegaban a Guatemala y, viceversa, los que se iban de Guatemala hacia esos territorios, eran parte de este circuito de circulación de tendencias políticas que fueron primordiales a la hora de pensar las movilizaciones. Con estas bases, se hace visible la importancia que conlleva el acto de juzgar a los militares.

La práctica judicial del fuero de guerra, como ejemplo de la forma en que eran juzgados los militares antes de 1818, es una vía para entender las bases doctrinarias y políticas desde dónde partirían las autoridades republicanas para afrontar el mismo problema. Ana Margarita Gómez reconstruye la evolución de la aplicación del fuero para la segunda mitad del siglo XVIII y los primeros años del XIX. De su estudio, se distinguen cuatro etapas clave.

La primera, 1773-1779, se distinguió por el papel preponderante que jugó el Capitán General del Reino de Guatemala como fuente de resolución de conflictos con respecto a la jurisdicción militar. Es decir, que las disputas entre autoridades civiles, acusados militares y la Audiencia sobre la aplicación del fuero militar tuvieron, al fin, en la figura del funcionario militar de mayor rango, a la persona que ejercía su función de instancia judicial. Durante estos primeros años, el cuerpo de oficiales no apareció con mucha frecuencia en la documentación judicial. Este periodo estuvo marcado por el intento de la Monarquía por controlar con mayor contundencia el gobierno local, pues tuvo lugar la polémica entre las altas autoridades civiles y militares que querían cambiar de sede a la capital del Reino y aquellos comerciantes y autoridades eclesiásticas que querían conservar la sede en Santiago de los Caballeros de Guatemala. ${ }^{11}$ Por otro lado, la Audiencia de Guatemala no contó con una presencia significativa de oidores criollos. Para 1775, ningún oidor tenía más de cinco años en el puesto y solo uno era originario del Reino. Entonces, el

${ }_{10}$ Cf. SZASZDI, Adan Nicolas Raoul y la República Federal de Centro-América, Seminario de Estudios Americanista, Madrid, 1958; TARACENA, Arturo “Algunos Oficiales extranjeros que combatieron en las guerras civiles de la República Federal de Centroamérica, 1826-1839" Boletín de la AFEHC: "Los procesos de construcción de identidades nacionales en Centroamérica a finales del siglo XIX y principios del siglo XX," Julio Septiembre 2010 http://afehc-historiacentroamericana.org/index.php?action=fi aff\&id=2503

${ }^{11}$ Los terremotos de Santa Marta en 1773 destruyeron buena parte de la Ciudad de Santiago de los Caballeros de Guatemala, hoy Antigua Guatemala. Esto motivó el intento de las autoridades coloniales por el traslado a un nuevo valle, justificando que dicho paso evitaría en el futuro una tragedia semejante. Sin embargo, la decisión de traslado también respondió a la postura regalista dominante en ese momento, que buscaba disminuir la influencia que la Iglesia y los grandes comerciantes ejercían sobre la vida política del Reino. Por el papel exitoso en el traslado que tuvo el Capitán General Martín de Mayorga, cuando fue removido del cargo en Centroamérica, fue nombrado como Virrey de la Nueva España. 
reforzamiento judicial del Capitán General en la disputa entre las esferas civiles y militares fue parte de una coyuntura en la que la Monarquía buscaba recuperar el control sobre la vida política del Reino, hecho que ayudó al reforzamiento del fuero militar y agregó condiciones favorables para la aplicación de las reformas militares, a partir de la década de 1760.

La segunda etapa, ca. 1779-1783, estuvo marcada por la guerra. El nombramiento de Matías de Gálvez como inspector de milicias y, luego, como Capitán General en 1779 ayudó a reforzar el papel de las milicias y cuerpos regulares en la vida política del Reino. Este periodo coincidió con la Guerra de Independencia de las Trece Colonias que implicó un nuevo conflicto entre la Monarquía española y Gran Bretaña. La organización miliciana y militar establecida por Gálvez le permitió realizar la campaña militar contra las ocupaciones militares inglesas en la Costa del Caribe Centroamericano. La difusión de los privilegios militares que acompañó este esfuerzo, marcó esta segunda etapa. Al mismo tiempo, la emisión de normas legales relativas al fuero militar y a la continuidad temporal del Auditor de Guerra, permitieron que se institucionalizan las prácticas judiciales con respecto a los militares y milicianos. Esto posibilitó que muchos más soldados solicitaran los privilegios que el fuero les consentía.

La tercera etapa, 1783-1808 fue de consolidación de las prácticas alrededor del fuero militar. El reconocimiento institucional que recibieron las milicias y militares después de las campañas militares en la costa caribeña de Centroamérica fue utilizado por los militares acusados de distintos delitos. Por esta razón, en los casos criminales relacionados a militares durante este periodo es visible la nueva dinámica. La autora cita el ejemplo de un Dragón del Regimiento de la Ciudad de Guatemala que dice: "yo podría ser mulato, indio, o incluso el diablo.... Todo lo que tengo por seguro es que Soy un soldado". Entre 1782 y 1791, a través de los casos analizados por el Auditor de Guerra, se reforzó la idea de que las disputas jurisdiccionales entre la esfera civil y militar se resolverían solo con que el acusado presentara su boleta de inscripción firmada por un oficial superior.

La cuarta etapa, 1803-1818, se distinguió por el cambio de dependencia en lo referente al Auditor de Guerra. Pasó de ser un integrante de la Audiencia a depender directamente del Capitán General. Este cambio reforzó el papel del Capitán al momento de ejercer su función judicial. Otro aspecto clave fue la expansión de la justicia militar hacia otras esferas de la vida civil, tanto gracias a la legislación real como por las manifestaciones de descontento que surgieron en distintos espacios del Reino durante ese periodo. A pesar de la aparente contradicción entre las dos esferas de la justicia, el objetivo final era la reafirmación de la ley y potestad real. Así, la aplicación severa del Capitán José de Bustamente y Guerra (1811-1817) respondió a una tendencia y a una coyuntura inestable, pero coherente con respecto a la transformación de la justicia militar. ${ }^{12}$

La independencia política entre 1821 y 1823, que dio pie a la formación de las Provincias Unidas de Centroamérica y luego a la Federación de Centro América, obligó a considerar al servicio militar como un espacio clave para la difusión de la ciudadanía. A lo largo de las primeras décadas de experimentación republicana, el servicio militar y miliciano fue ocupado sobre

\footnotetext{
${ }^{12}$ GÓMEZ, Ana Margarita "Al servicio de las armas. The Bourbon Army of Late Colonial Guatemala, 1762-1821", Tesis de doctorado, University of Minnesota, 2003, pp. 103-195.
} 
todo por los integrantes de las llamadas castas (mulatos, mestizos, pardos, etc). A eso se sumaron algunas unidades indígenas en momentos de guerra, tanto de Momostenango como de Chiquimula. ${ }^{13}$

El papel del fuero militar y, su consecuencia directa, la forma más adecuada para juzgar a los militares estuvo en el centro de la legislación militar y ciudadana durante las décadas de 1820 y 1830. La emisión de distintos reglamentos tuvo lugar en contextos marcados por las guerras federales (1826$1829,1831-1832$ y 1837-1840) y batallas en el Estado de Guatemala, El Salvador y Honduras (1832, 1835 y 1837-1839). En este sentido, la atención se enfocará en los reglamentos del Estado de Guatemala para entender los casos específicos que se discutirán.

La Constitución del Estado de Guatemala de 1825, vigente hasta 1839, dividió a las tropas en regulares y milicias (activa y cívica), dejando abierto el tema del fuero a la reglamentación específica que se iba a emitir pero que la Primera Guerra Federal de 1826-1829 frenó. Aunque es preciso ahondar aún más en la investigación, una primera impresión indica que durante el conflicto las causas militares se sustentaron en la tradición de la Ordenanza Militar de 1768. Una vez finalizada esta contienda, la reorganización de los ejércitos federales y estatales se volvió una tarea urgente para evitar que los derrotados pudieran retomar el poder. El 30 de julio de 1830 se emitió el nuevo reglamento sobre el "Ejército y su formación", que establecía las condiciones para el reclutamiento y número de las nuevas unidades militares. Expresaba también que el fuero militar estaba reducido a los oficiales en activo de alta jerarquía y al Batallón "Libertad" y el escuadrón "Constitución". ${ }^{14}$ Esta última condición era clave para entender los balances políticos territoriales desde el plano militar y judicial. En la Ciudad de Guatemala se mandó a organizar dos batallones de infantería, ("Unión" y "Libertad") y en Sacatepéquez, otro batallón con el nombre "Restaurador" y un escuadrón llamado "Constitución". Es decir, que el fuero militar permanente se reducía una parte de las tropas más cercanas al gobierno del Estado la Ciudad de Guatemala y Antigua. Ante las dificultades financieras y organizativas para levantar al Ejército del Estado, unos meses después se reorganizaron las milicias, como una forma más barata y práctica para contar con tropas en caso de guerra. El fuero militar se ensanchó a "los individuos que estén de servicio y quedan exentos de la capitación el año en que lo presten". ${ }^{15}$ La ampliación de los alcances del fuero militar formaba parte del nuevo orden político posterior a la guerra en el que se reordenaron las divisiones militares y los oficiales consiguieron mayor protagonismo. Esto fue confirmado con la reorganización general militar del Estado con el reglamento de 30 de octubre de 1832. Otras reglamentaciones aseguraban el fuero para aquellos en servicio permanente y los integrantes de los cuerpos legionarios, unidades que al parecer nunca se constituyeron completamente. En 1834 y 1835 se ratificó la extensión del fuero a todos los integrantes del ejército, orden confirmada en junio de 1837, en plena rebelión de La Montaña (1837-1839), que marcaría el fin de la Federación Centroamérica y el gobierno de Gálvez. Estos cambios se produjeron a raíz de nuevos conflictos (1831-32) y del proceso de reforma política y económica de Mariano Gálvez (1831-1838) como Jefe del Estado de Guatemala. Posteriormente, con la llegada al poder como

\footnotetext{
${ }_{13}$ TARACENA, Arturo et al Etnicidad, estado y nación en Guatemala, 1808-1944, CIRMA, Antigua Guatemala, 2002, p. 190.

${ }^{14}$ Biblioteca Nacional de Guatemala, Colección Valenzuela (NG-CV), Hojas Sueltas, 1830.

${ }^{15}$ Decreto de 15 de noviembre de 1830, BNG-CV, Hojas Sueltas 1830.
} 
comandante del Ejército, mas no como presidente, de Rafael Carrera en 1839, la reglamentación sobre el fuero recuperó expresamente las pautas ya mencionadas antes de la independencia, sobre todo aquellas de 1768, 1781 y 1800, asegurando el fuero a todos aquellos integrantes de las milicias y cuerpos militares (decretos de 1840 y 1846). Esta situación se mantuvo hasta el cambio político de 1871 y la llamada Reforma Liberal. ${ }^{16}$

¿Cuál fue la herencia dejada por estos reglamentos en la práctica judicial militar? Los casos que se abordarán sucedieron durante la década de 1850; década marcada por cierta estabilidad al interior de Guatemala gracias a un nuevo orden político, definido por la Constitución de 1851, el Concordato con el Vaticano y la Presidencia Vitalicia de Rafael Carrera. Es decir, un periodo de consolidación política que no se tradujo en la ausencia de pronunciamientos en contra del gobierno pero que sí le facilitó, a través de las alianzas construidas a lo largo del territorio, afrontarlos. Estas razones motivaron la atención sobre los registros judiciales militares de esos años, pues su exploración permitirá apreciar cómo funcionaba este nuevo orden con respecto a los militares.

En junio de 1852, el reo Mariano Monterroso, acusado de varios delitos en calidad de integrante de las fuerzas armadas de Guatemala, fue sentenciado a prisión por la Corte Suprema de Justicia. Sin embargo, en contra de las opiniones de jueces y allegados en el gobierno, el Presidente Rafael Carrera ordenó la liberación inmediata del acusado. ${ }^{17}$ Ese mismo año, Carrera sentenció a pena de muerte a varios soldados y oficiales, antiguos integrantes de la guarnición de la Ciudad de Guatemala, concentrados en el Fuerte San José, al sur de la Ciudad de Guatemala. Estos hechos ocurrieron el 12 de agosto. ${ }^{18}$ Los dos casos exhiben los extremos del abanico de posibilidades a las que estaban sujetos los integrantes de las fuerzas armadas a la hora de enfrentar la justicia.

Mariano Monterroso era un integrante de las milicias de Santa Catarina Pinula, una población indígena con un componente no indígena importante ubicado cerca de la montaña de Canales, al suroriente de la Ciudad de Guatemala. En caso de invasión desde San Salvador o la incursión de partidas de tropas no allegadas al gobierno, Pinula era uno de los primeros lugares de defensa para la capital de la República. En ese sentido, contar con tropas fieles de ese lugar era una de las medidas de seguridad urgentes.

Pero a este hecho se sumaba otro aspecto clave. Los llamados Lucíos, varias partidas de grupos armados relacionados con tensiones agrarias sobre todo en el oriente de Guatemala y actores fundamentales de las luchas políticas entre 1847-1852, tuvieron como espacio privilegiado de acción las montañas cercanas a Pinula, en especial con dirección norte y noreste. Durante los años 1849 y 1850, el Gobierno intentó sofocar a las partidas rebeldes de esa zona a través de una campaña militar severa, el traslado de familias y aldeas enteras hacia lugares bajo vigilancia y la asignación de tierras. Esto tuvo como consecuencia que una parte importante de la base social de los rebeldes en la zona se rompió. Antiguos insurgentes se pasaron a las filas del Gobierno, combatiendo muchos de ellos en la Batalla de la Arada, a inicios de 1851, cerca

\footnotetext{
${ }_{16}$ PINEDA MONTT, Manuel Recopilación de las leyes de Guatemala, Imprenta La Paz, Guatemala, 1872, T. II, pp. 660-743; MARURE, Alejandro Catálogo de las leyes promulgadas en el Estado de Guatemala, desde su creación en 15 de septiembre de 1824 hasta el 5 de octubre de 1841, Imprenta de La Paz, Guatemala, 1841, pp. 57-62.

${ }^{17}$ El caso está en Archivo General de Centroamérica (AGCA), B, Leg. 28557, Exp. 18.

${ }^{18}$ WOODWARD, Ralph Lee Rafael Carrera y la creación de la República de Guatemala, 1821-1871, CIRMA, Antigua Guatemala, 2003, pp. 384-5.
} 
de la frontera oriental, gracias a la cual el Gobierno derrotó a los ejércitos combinados de Honduras y El Salvador. Esa batalla es considerada como el punto de partida del orden conservador en toda su profundidad en Guatemala. ${ }^{19}$

Entonces, el origen de Monterroso es muy significativo por el apoyo que recibió de Rafael Carrera, el hombre fuerte y dirigente de Guatemala, desde esa zona. La condena emitida por el Consejo de Guerra había sido de 6 años en el Presidio de San Felipe, ubicado sobre el principal ingreso marítimo desde el Caribe guatemalteco cuya población presidiaria, militar y civil era afectada con frecuencia de enfermedades tropicales. Se trataba de una condena severa pero no infrecuente durante el periodo republicano y colonial. Parece ser, según argumentaba el regente de la Corte, que esa condena ya estaba rebajada en una tercera parte en consideración a los servicios prestados por Monterroso durante la Batalla de la Arada.

Sin embargo, la disputa surgió porque el miliciano fue sacado de la cárcel por orden del Presidente Carrera e integrado al Batallón $1^{\circ}$. de línea de Guatemala. Según el regente, esta "orden que acaso fue dada sin conocimiento del Ministerio [de Gobernación], tal vez sin la debida información de los hechos". El tono diplomático respondía al cuidado que tenía la Corte para intentar mantener la condena pero sin enojar al Presidente y sus bases sociales, es decir, los mismos soldados. Por esta razón, al final de su escrito, el Regente pedía que Monterroso cumpliera su condena. En la respuesta del Ministro, no del Presidente, se argumentó que esa medida había sido tomada "en atención a que dicho reo, tanto en la acción de la Arada, como en otras varias, se ha comportado bien, haciéndose por ello acreedor a alguna consideración, y con la mira de que, de esta manera, al mismo tiempo que se castigue su delito, se puedan utilizar sus servicios." Las autoridades asumieron que, según antiguas leyes, se podía designar al servicio de las armas a criminales condenados. El meollo de la tensión se hallaba en si la Corte podía mantener su punto de vista legal y jurídico frente a las necesidades políticas del Presidente.

En una nueva misiva, el Regente de la Corte reconoció que el Presidente tenía la potestad del perdón en el caso de la pena capital pero de eso no se deducía que "en cualquier caso pueda el Presidente conmutar las penas impuestas por los Tribunales de justicia" porque en ese caso "de seguro que irían todos los reos, después de agotar sus recursos ordinarios, a solicitar la conmuta. Si se concedía a todos indistintamente, ya serían inútiles los tribunales (...) y es de interés general que el Jefe del Gobierno no se manifieste en función alguna de la administración donde pueda haber algo de desagradable $u$ odioso". En forma clara pero delicada, el Regente buscaba convencer al Presidente Carrera, a través de su Ministro de Gobernación, de la conveniencia de respetar la decisión de la Corte para garantizar que su reputación fuese conservada sin mancha alguna. La estrategia del Regente se vuelve comprensible al recordar que la figura de Rafael Carrera y su prestigio se construyeron a partir de su papel de jefe insurgente y militar, como repartidor de justicia a través de la asignación de tierras y el cese de contribuciones directas. Cada una de estas facetas se hizo visible en sus visitas a los departamentos, como sucedió después de derrotar a los notables de Quetzaltenango en su intento por formar el Estado de Los Altos (1838-1840). La resolución del caso se atrasó varias semanas, evidenciando el poder que Carrera

\footnotetext{
${ }^{19}$ SARAZÚA, Juan Carlos “Fuerzas militares para defender al Estado: Guatemala 1823-1863” en GARAVAGLIA, Juan Carlos et al. Las fuerzas de guerra..., cit., pp. 33-58.
} 
ejercía. En el mes de septiembre, casi tres meses después de iniciada la tensión entre la Corte y el gobernante, la resolución mandó que Monterroso fuese a presidio, tal como el Regente esperaba, y no al servicio militar. ${ }^{20}$

En apariencia menor, este caso tuvo un impacto mayor de lo esperado. Al igual que en otros departamentos del país, en Chiquimula se esperaba con ansias la resolución. El motivo de tal inquietud se originaba en el rapto y violación de la joven Juana Salazar, hecho ocurrido en la cabecera departamental. El Juez de $1^{a}$. Instancia de ese departamento recibió la orden presidencial de liberar a los tres acusados que, al parecer, eran también militares. Por esta razón, el proceso se detuvo mientras el caso Monterroso se resolvía. Una vez que el Presidente aceptó seguir los parámetros establecidos por la Corte, se envió una comunicación por parte del secretario de esta última para notificar que se podía seguir el proceso adecuado. El secretario le decía al Juez de Chiquimula que

"me es grato el poder asegurar que la Corte debe contar con
que el Gobierno apoyará siempre la justicia y sostendrá los
actos legales de los tribunales y su independencia, como a ella
misma le consta, pues puede asegurarle que nunca ha sido más
completa desde la Yndependencia, por la ninguna ingerencia
que habrán experimentado en sus actos, situación que apenas se
habrá visto igual en los Gobiernos precedentes".

La deserción siempre fue una de las acciones presentes en la organización de las unidades militares durante el siglo XIX. El objetivo aquí es mostrar dos momentos vistos a través de este lente para entender los balances políticos. El primer caso fue el de Escolástico Rodenas, soldado federal, ocurrido en $1830,{ }^{21}$ en una coyuntura de transformación del orden legal castrense y de discusión sobre justicia militar. Después de la victoria del Ejército Aliado Protector de la Ley, en abril de 1829, la organización de los ejércitos federales y estatales, bajo la conducción de los liberales radicales cuya figura más prominente fue Francisco Morazán, se tornó urgente debido a la deserción de parte importante del Ejército vencedor $y$, la consiguiente, proliferación de bandas de ladrones que afectaban los caminos. En este sentido, la conservación de la disciplina era el primer objetivo. El 16 de octubre de 1830 se reportó a la Comandancia General de la Federación que Escolástico Rodenas y Fermín Sosa estaban presos en la cárcel pública de la Ciudad de Guatemala. El primero fue acusado de ser el responsable de heridas y el segundo por homicidio. Ambos eran soldados del Batallón $2^{\circ}$. Federal. Al parecer, en el momento de ser capturados, los dos individuos solicitaron su derecho al fuero, pues las autoridades de la Corte Superior de Justicia pidieron las respectivas constancias a la Comandancia General. La contestación de las instancias militares sacó a luz que ambos acusados asumían su papel de soldados para poder usar el fuero como una protección. Sin embargo, las unidades militares a las que supuestamente estaban adscritos, no se habían formado todavía. Esto implicaba que la solicitud de protección del fuero no correspondía. De igual forma, la acusación mayor con respecto a la deserción no era aplicable. Notable es que las

\footnotetext{
${ }^{20}$ Brian Connaughton sugiere, en un trabajo en curso, la continuidad de tendencias liberales en los funcionarios de la Corte Suprema de Justicia después del fin de la Federación, 1840, y el desempeño de un papel no valorado todavía en la construcción de políticas públicas. CONNAUGHTON, Brian "El fiscal de la Suprema Corte: templador de la política pos-liberal en Guatemala", Ponencia en la mesa de Historia Política, XIII Congreso Centroamericano de Historia, Tegucigalpa, julio de 2016. Agradezco al autor darme acceso a su investigación en proceso.

${ }^{21}$ AGCA, Índice 31, Guatemala, Juzgado de 1ª Instancia, leg. 4 exp. 212.
} 
autoridades fueron muy cuidadosas en supervisar la calidad jurídica de Rodenas para mantener la disciplina.

El segundo caso tuvo lugar en la década de 1850 en un contexto muy diferente. Sullivan González afirma que el discurso difundido por los clérigos y la Iglesia jugó el papel de base para construir la imagen de la nación guatemalteca, alejada del centroamericanismo de los liberales, articulada a través del "pacto" entre Dios y el país. Este nacionalismo se expresó, a nivel local, por medio de los ritmos de reclutamiento durante los conflictos de la década de 1850 y 1860. Sullivan muestra que la amenaza extranjera de 1851 intento de invasión por parte de Honduras y El Salvador- obligó al Gobierno a hacer grandes esfuerzos frente al poco éxito de los reclutamientos militares. En cambio, en 1863, ante una nueva guerra con El Salvador, la incorporación de contingentes fue mucho más amplia. Sullivan argumenta con claridad que este cambio era el resultado del trabajo realizado por la Iglesia para difundir una imagen de la nación en todos los niveles. ${ }^{22}$ La campaña de 1857 de los Capuchinos en el oriente de Guatemala, zona siempre conflictiva, fue el mejor ejemplo. Una segunda epidemia de cólera transmitida por el retorno de las tropas guatemaltecas que habían ido a Nicaragua por la Campaña Nacional, la guerra contra William Walker, fue el marco para mayor descontento en el oriente de Guatemala. Las campañas de los capuchinos para pacificar la zona a través de misas, confesiones y bautizos fueron un éxito. ${ }^{23}$ Estos hechos eran indicios de la necesidad constante de negociar por parte del Gobierno con los soldados y unidades territoriales para evitar una rebelión en un contexto de guerra. Los casos discutidos a continuación tuvieron lugar en esa coyuntura y muestra las facetas de dicha negociación.

El primer caso fue el del soldado Manuel Iriondo quien fue encontrado culpable de deserción reincidente, robo de prendas nacionales y heridas al Alcalde $1^{\circ}$. de Tejutla, cerca de la zona fronteriza con México. La cadena de faltas a la reglamentación militar tuvieron lugar en agosto y septiembre de 1857, poco después del fin de la guerra contra William Walker. El Consejo Ordinario de Guerra lo condenó a cuatro meses de prisión, pero el Fiscal encargado de la causa defendió una condena mayor, al menos de ocho meses:

"la deserción fue consumada dos veces, con hurto de prendas nacionales, y la última con escalamiento del cuartel; $y$ aunque es cierto, que en el estado actual de nuestro ejército, no pueden aplicarse con todo rigor las penas de la ordenanza militar, no han de ser tan débiles [las condenas] que se hagan insuficientes para corregir a los culpables". ${ }^{24}$

A inicios de noviembre del mismo año, la Corte Suprema aceptó la condena de 3 meses de cárcel, a partir de la situación política y militar descrita por el Fiscal y por el papel ejemplar que jugó Iriondo en el Lazareto de Jocotenango (al norte de la Ciudad de Guatemala) durante la epidemia de cólera del mismo año. Al mismo tiempo, Iriondo calificaba en el indulto general decretado el 21 de septiembre. De modo que se dispuso su liberación inmediata.

Otro caso semejante fue el del soldado de milicias Ángel Hernández, acusado de deserción y heridas a un oficial superior. A pesar de la gravedad para la cadena de mando, el cargo relacionado con el ataque al oficial Primo

\footnotetext{
${ }^{22}$ SULLIVAN-GONZÁLEZ, Douglas Piety, power..., cit., p. 107.

${ }^{23}$ SULLIVAN-GONZÁLEZ, Douglas Piety, power..., cit., pp. 56-58.

${ }^{24}$ AGCA, Índice 31, Guatemala, Juzgado de 1a . Instancia, leg. 27A, Exp. 7, fol. 1v.
} 
Roche fue descartado por el Consejo en su dictamen de febrero de 1857. La Comandancia General de Guatemala apoyó esta decisión. Sin embargo, en el caso de deserción, todas las instancias judiciales aceptaron las pruebas del delito, pero tanto el Fiscal de la Corte y el Consejo de Guerra, acordaron que la pena fuese de cuatro meses contados desde el momento de captura. Esta postura implicaba que el tiempo de prisión faltante era mínimo. Ahora bien, en la opinión del Procurador de Pobres la condena de cuatro meses era excesiva "en justicia nuestros soldados no debieran ser castigados por este delito, porque en realidad no son soldados ni cometen este delito, por cuyo motivo, y solo para ejemplo de los demás, puede imponerse alguna pena." El Fiscal de la Corte Suprema de Justicia reconoció también en su dictamen que las condiciones en que se realizaban los reclutamientos para la guerra constituían un elemento de descargo para el castigo reducido de cuatro meses por deserción. ${ }^{25}$

Pocas semanas después, en el dictamen del mismo fiscal, Andrés Andreu, sobre un oficial que escandalizó e hirió a subalternos se puede observar la lógica que subyace la serie de dictámenes benignos que acompañaron los juicios militares en el periodo 1856 y 1857:
"en tiempos de revolución debe haber más lenidad en los castigos de los delitos militares; pero en tiempo de paz, es necesario reprimir los excesos para que la inmoralidad no cunda en el ejército, y podamos alguna vez verlo organizado, conforme al espíritu de sus peculiares leyes." 26

Los casos presentados muestran que la coyuntura de 1856-1857, expresada en la campaña militar contra William Walker en Nicaragua y la epidemia de cólera que atacó a todo el Istmo, la justicia militar se guió por cierta indulgencia hacia los delitos militares como parte de una estrategia mayor aplicada con sumo cuidado desde la década de 1840 pero que la consolidación interna de Guatemala después de 1851 había permitido materializar con mayor profundidad: el fuero militar como herramienta clave de la negociación política entre algunas poblaciones y el Gobierno para centralizar al Estado. En agosto de 1843, Rafael Carrera escribió a la Asamblea, quejándose de la tardanza en autorizar el fuero militar, acusando a la Asamblea misma de buscar la disolución de las "fuerzas militares". ${ }^{27}$ La Asamblea fue disuelta en 1844. Después, hubo un nuevo intento fallido para emitir una carta magna en 1845. Un año después, fue emitida la nueva legislación aprobando el fuero. Es decir, que la aplicación del fuero durante tiempo de guerra que aquí se ha analizado, fue solo un momento de la estrategia mucho más amplia que buscaba garantizar la participación de amplios sectores en las fuerzas armadas. Así, la lenidad tuvo mucho de político. Y las consecuencias se hicieron sentir años después. En la década de 1860 fueron comunes las quejas de funcionarios civiles denunciando que los militares, en los pueblos que aportaron la mayor parte de contingentes en las guerras de esos años, se consideraban fuera de la jurisdicción civil. ${ }^{28}$

\section{Chiapas}

\footnotetext{
${ }^{25}$ AGCA, Índice 31, Guatemala, Juzgado de 1 ${ }^{\mathrm{a}}$. Instancia, leg. 27A, Exp. 21, fol. 3v-4v.

${ }^{26}$ AGCA, Índice 31, Guatemala, Juzgado de $1^{\mathrm{a}}$. Instancia, leg. 27A, Exp, 16, fol. 7v.

${ }^{27}$ SARAZÚA, Juan Carlos "Santa Rosa y Chiquimula...", cit., p. 230.

${ }^{28}$ SARAZÚA, Juan Carlos, "Fuerzas militares...", cit.
} 
La militarización de la vida de Chiapas después de la coyuntura de 1821-1824 dependió de dos factores: la incorporación de población masculina local a las milicias y cuerpos organizados, sobre todo alrededor de Comitán, Tuxtla y Ciudad Real; y segundo, a la circulación de unidades militares provenientes de otros Estados de México que arribaron como parte de las pugnas militares y políticas ocurridas durante la primera mitad del siglo XIX. Los dos casos aquí mencionados se inscriben en esas dinámicas.

La incorporación de Chiapas al proyecto mexicano entre 1823 y 1826 tuvo como objetivo principal garantizar que el probable canal interoceánico planificado en el Istmo de Tehuantepec quedara bajo control del gobierno mexicano. Al mismo tiempo, les aseguró a las elites de Ciudad Real y algunos notables de otras poblaciones la conservación de los vínculos hacia la Nueva España. La condición de frontera sin delimitación detallada de los límites, obligó a mantener fuerzas militares provenientes de otros Estados para evitar que varios sectores de Comitán y Tuxtla arrebataran el poder y pusieran en peligro la nueva frontera. A esto se sumó la condición de territorio neutral que tuvo Soconusco entre 1824 hasta 1842, con la ocupación ordenada por Santa Anna. ${ }^{29}$

En este sentido, la aduana federal establecida en Comitán-Zapaluta (actual La Trinitaria) tenía como responsabilidad vigilar y detener el "contrabando" que había entre Los Altos de Guatemala y la zona central de Chiapas, que no era más que el comercio que se mantenía de los viejos circuitos mercantiles coloniales entre esos territorios. Los guardas y militares del destacamento ubicado en este punto eran originarios de San Luis Potosí, región marcada por los acontecimientos posteriores al movimiento del Cura Hidalgo en 1810 y la estrategia de contrainsurgencia aplicada ahí. Estas condiciones produjeron la incorporación significativa de hombres adultos a las filas milicianas y militares. Benavides Martínez dice con claridad:

"Podríamos hablar de dos tipos de milicianos de los regimientos potosinos durante la guerra [1810-1821]. La práctica totalidad eran jóvenes y sin compromisos familiares, pero los vecinos de la provincia de San Luis eran predominantemente hombres de campo, mestizos, analfabetos, y que servian en los cuerpos de dragones, mientras que entre los procedentes de otras regiones del virreinato, en gran parte alistados en el batallón de infantería, había un importante componente de blancos, dedicados a oficios, y que estaban alfabetizados." 30

El panorama que Benavides proporciona es clave porque permite entender el origen de los guardas y militares ubicados en Zapaluta, pues eran dragones provenientes de Alaquines, San Luis Potosí, que pueden ser incluidos en la descripción que el autor hace de los dragones: mestizos provenientes del campo. Y los marcadores étnicos que habían asumido como militares mestizos lo expresaban en sus declaraciones a las autoridades judiciales de Comitán, lugar al que eran conducidos los traficantes y sus cargas después de la captura, como sucede con el Guardia Miguel Baldano, que mencionó a unos "indios de

\footnotetext{
${ }^{29}$ VÁSQUEZ, Mario "Chiapas mexicana. Política regional e intereses de estado en la gestación de la frontera entre México y Guatemala, 1821-1842", Tesis de Doctorado, UNAM, México, 2014. 30 BENAVIDES MARTÍNEZ, Juan José De milicianos del Rey a soldados mexicanos. Milicias y sociedad en San Luis Potosí (1767-1824), CSIC-Universidad de Sevilla, Madrid, 2014, p. 352. Énfasis mío.
} 
San Sebastián, de la República de Centro América". ${ }^{31}$ En este contexto, aconteció el caso del Guarda Roberto García.

Durante los últimos días de marzo de 1827 se realizó la incautación de varias cargas de maíz en la casa de García, que era uno de los encargados de patrullar las rutas desde Guatemala hacia Comitán y los Altos de Chiapas. Las autoridades judiciales rápidamente iniciaron las indagatorias para averiguar sobre "hecho tan escandaloso (...) a quién y a los que resultaren cómplices se les aplicará la pena que merezcan conforme a la ley" ${ }^{32}$ En las declaraciones de los guardas y militares que hacían las rondas en Zapaluta, se aclara con detalle la forma en que procedían estas patrullas, la autonomía que tenían para denunciar a los que consideraban contrabandistas y los espacios que vigilaban. Los guardias Ramón de Asúa y Eugenio Olgin, ambos provenientes al igual que García de San Luis Potosí, iban haciendo su ronda de inspección en distintas casas con la autorización del Juez de Partido de Los Llanos (Comitán). Encontraron varias cargas de trigo, las que, siguiendo las órdenes que tenían, iban a ser enviadas al Juez; pero el guarda García se opuso, explicando que esas cargas estaban bajo cuidado de su esposa quien las había recibido de unos "indios" pero con intención de conducirlas a la aduana. Debido al trabajo acumulado, los testimonios de los guardas restantes no se recibieron hasta varios meses después. En julio, o sea casi tres meses después de la incautación, el segundo guarda testificó. Ramón de Asúa dijo que ya habían recibido denuncias sobre García, por eso, este no era parte de la patrulla y fue sorprendido en su casa con las cargas de trigo. A pesar de que escapó, unos días después uno de los guardas lo capturó en las proximidades de Zapaluta, venía de un viaje de Guatemala que corroboraba "el malicioso procedimiento de aquel guarda que debe tenerse por delincuente". Cualquiera de los elementos mencionados en los testimonios hacía de García el responsable directo, a pesar de sus intentos por descargar la culpa en su esposa y unos desconocidos. Sin embargo, la trama era más compleja. García, en su testimonio, decía que varios ciudadanos de Zapaluta y Comitán podían dar fe de su buen comportamiento, pues había aprehendido el trigo con toda la intención de depositarlo ante las autoridades de la aduana. Por el contrario, con los apellidos mencionados (Herrera, Gordillo, Villatoro), parece indicar más bien que se trata de socios de García en el contrabando, pues algunos de ellos aparecieron en los expedientes posteriores sobre el mencionado delito. La hipótesis sería que el gran poder que se les había conferido a los guardas para hacer denuncias e incautaciones era usado, por el contrario, para favorecer a alguna de las redes de comercio en detrimento de otras. ${ }^{33}$

Sin dejar a un lado el interés sobre los guardas y su papel en el contrabando, el caso de Roberto García también es significativo en otro aspecto no menos importante: las formas de negociar la fidelidad de las tropas en una zona de frontera. El Guarda García volvió a sus actividades después de cuatro meses en la cárcel. El justificante estaba plasmado en una carta de julio de 1827: la relativa escasez de guardas. En el fondo, lo que estaba en juego era la conservación de un delicado equilibrio entre las exigencias federales, las redes de contrabando en las que se inscribían los guardas y otros comerciantes y, por último, la ya mencionada fidelidad. En cuanto a esta última, según la legislación

\footnotetext{
${ }^{31}$ Casa de la Cultura Jurídica de Tuxtla Gutiérrez (CCJ-Tuxtla Gutiérrez), JD-1 (Primer Juzgado de Distrito), Caja 2, 1827-1828, exp. 52.

${ }^{32}$ CCJ-Tuxtla Gutiérrez, JD-1 (Primer Juzgado de Distrito), Caja 2, 1827-1828, exp. 40, abril de 1827, fol. 2. Los párrafos siguientes se basan en este expediente.

${ }^{33}$ Es una hipótesis que el trabajo en curso de la Dra. Amanda Torres aclarará.
} 
federal, los guardas tenían garantizado una parte del comiso realizado, casi siempre, una parte significativa después de cubrir las costas judiciales. En este sentido, ante la permanencia a lo largo de los años del mismo grupo de guardas, a pesar de las tensiones internas (como se manifiesta en los testimonios del caso aquí tratado), fue necesario el perdón de estos cargos menores. Roberto García lo expresaba en una carta de abril de 1831, en la que se pedía su pronto retorno pues hacían falta guardias. En su defensa en mayo de ese año, García dijo con claridad que "califican mucho más mi inocencia el procedimiento del Sr. Comisario General en haberme continuado de guarda los cuatro años corridos desde aquella época hasta el presente, sin embargo, de la acción intentada contra mi persona". La sentencia final fue favorable en parte a García, pues lo declaró inocente, aunque sin derecho al comiso respectivo. Pero el juez le pide que "cumpla en lo sucesivo, con más actividad y esmero en las funciones de su destino, sin dar lugar otra vez a que se sospeche de su conducta, por omisión o negligencia."

\section{Rebeldes}

Para discutir algunos puntos sobre la forma de juzgar a los rebeldes, retomo el caso de un ciudadano francés, Carlos Barneond, quien se pasó a las filas de los Lucíos (1847-1851). Se trataba del hijo de un comerciante francés radicado en Guatemala alrededor de 1829, que había nacido en París en 1826 y aparecía como avecindado en Escuintla al momento de su captura en $1850 .{ }^{34}$ Hay pocos datos disponibles, parece que estaba en el negocio del aguardiente en dicha zona, algo no muy extraño si se toman en cuenta otros casos de franceses en el mismo negocio. Ahora bien, según las indagatorias judiciales, Barneond había tomado partido por Vicente $\mathrm{Cruz}^{35}$ en el momento en que se había rebelado contra el gobierno, es decir, en el periodo clave de mediados de 1848, cuando Vicente y Serapio Cruz habían formado uno de los grupos en plena rebelión contra el gobierno de Rafael Carrera. Luego de un proceso de negociación con muchas complicaciones, estos rebeldes se integraron a las filas del gobierno para finales de enero de 1849, cuando Carrera estaba en exilio mexicano pero su retorno era cercano. En este mismo momento, Barneond se acogió a la amnistía emitida por el gobierno, medida dirigida a garantizar la fidelidad de los seguidores de los Cruz pero ahora como parte del Ejército de Guatemala. Sin embargo, en una fecha sin determinar, Barneond se reintegró a las filas de otra de las facciones rebeldes, la de León Raymundo hasta la muerte de este último, en septiembre del mismo año. Considerado por la "voz pública" como uno de los rebeldes, fue apresado en julio de 1850 en la finca el Zarzal, ubicada en el municipio de Villa Nueva, al sur de la Ciudad de Guatemala. Fue capturado con un fusil del gobierno, hecho que era considerado un delito grave para ese momento. Los testimonios reunidos durante el juicio apuntaron a la responsabilidad del francés en cuanto a su participación en el rescate de Cándido Arreces, uno de los últimos dirigentes Lucíos y a la posesión del arma en cuestión. Por estar bajo la jurisdicción militar, fue condenado a muerte y

\footnotetext{
${ }^{34}$ La principal fuente para este estudio es el juicio transcrito a las autoridades francesas. Está en, AGCA, B Leg. 4314.

${ }^{35}$ Vicente Cruz había sido, junto a su hermano Serapio, uno de los lugartenientes más fieles de Rafael Carrera durante la Rebelión de la Montaña (1837-1839), ocupó varios cargos importantes como militar, incluyendo la Vicepresidencia. A mediados de la década de 1840 había mostrado cierto acercamiento con algunos políticos del ala liberal derrotada en 1840.
} 
fusilado la segunda semana de octubre de 1850, en Mataquescuintla, "uno de los principales lugares-teatros de la guerra civil". ${ }^{36}$

Por la forma de proceder por parte de las autoridades durante el juicio, este documento se vuelve una buena oportunidad para conocer algunas facetas del proceso de represión por parte de las autoridades y de algunos elementos clave de la última etapa de los Lucíos (1850-1851). Para empezar ¿cómo fue capturado y llevado ante las autoridades militares? El oficial Simón Bolaños comunicó a sus superiores el 12 de julio de 1850 sobre la infructuosa búsqueda de Cándido Arreces por los alrededores de Villa Nueva. Sin embargo, la patrulla tuvo el éxito de capturar a Barneond en posesión de un fusil del gobierno. Bolaños afirma que las razones para su captura fueron el fusil, el haberlo visto preso en el Batallón $1^{\circ}$. de línea y por la "voz pública" que lo designó como miembro de la partida de Arreces. ${ }^{37}$ Conviene rescatar que la voz pública era una de las principales herramientas durante los juicios pues a través de ella se establecía la honorabilidad y, en gran medida, la culpabilidad de los acusados. Y será en este caso uno de los aspectos para justificar la condena. Pero volviendo al proceso, la indagatoria aporta otro punto importante: la participación de los labradores cercanos a las fincas y sus administradores como sujetos que cumplían la función de vigilancia. La imposibilidad de cubrir todo el territorio con tropas, obligó a las autoridades a presionar a estos actores locales para que fuesen parte de la política de reasentamiento para la población dispersa y para vigilancia sobre las incursiones de las partidas de Lucíos. Una política que se acrecentó desde inicios de 1850. En el momento de la captura, el Administrador de la finca El Zarzal, propiedad de Raymundo Arroyo, antiguo ministro del gobierno y negociador con los Cruz del acuerdo de enero de 1849, recibió noticias de un posible ataque por parte de Arreces. Por esta razón, buscó la forma de deshacerse de Barneond. Paulino Calderón, labrador de la finca, ayudó en este sentido pues fue el conducto para intentar la captura del sospechoso y darle aviso a Bolaños. En su declaración, Barneond refutó en forma sistemática la acusación hecha por el fiscal. No aceptó la responsabilidad de la posesión de un fusil del gobierno y negó haber colaborado en el rescate de Arreces en la cárcel de Petapa. No obstante, no podía negar su participación en la facción de Vicente Cruz en 1848, detalle que conviene conservar.

Frente al juez desfilaron otros testigos que conformaron la voz pública que permitió a las autoridades la reconstrucción de las andanzas de Barneond. Así, fueron registrados los testimonios del Administrador de la finca El Zarzal, los "complices" en el rescate de Arreces, de este último y antiguos compañeros de Barneond en la facción de Vicente Cruz. De esta manera, el fin del juicio se cumplió pues se "demostró" que Barneond había participado en la facción de León Raymundo (fallecido en septiembre de 1849); había sufrido prisión por una trifulca con un antiguo compañero de armas en las tropas del gobierno para luego pasar a ser parte de los movimientos más fragmentados de los Lucíos sobrevivientes. Así, había ayudado en la liberación de Arreces, hecho considerado grave porque ponía en riesgo la política de pacificación dirigida con ferocidad por Rafael Carrera como comandante militar en 1850. Pero aún más importante era el papel que desempeñó como enlace entre los rebeldes y las poblaciones de Escuintla y la Costa sur, como lo recordó uno de los testigos "que muchas comisiones las desempeñaron juntos (...) las de andar por los

\footnotetext{
${ }^{36}$ AGCA, B Leg. 4314. Carta al Cónsul de Francia, 17 de noviembre de 1850.

${ }^{37}$ AGCA, B Leg. 4314. Carta al Corregidor y Comandante, Amatitlán, 12 de julio de 1850.
} 
pueblos y trapiches recogiendo gente, bestias y todo lo que les servía para la guerra." 38

Esta última faceta de Barneond mostrada por uno de los testigos es clave en todo el proceso judicial y el papel del Inglés Barneon en la lógica militar y política seguida por los rebeldes. Conocido como extranjero o al menos chapetón entre los habitantes de los pueblos y trapiches, el francés tuvo a su cargo una de las tareas más complejas para los rebeldes: la recolección de personas y recursos para el sostenimiento de las tropas en movimiento. Ha sido recalcada por la historiografía sobre la guerra que una parte importante del reclutamiento por los grupos rebeldes y ejércitos de la época se articuló alrededor de la incorporación forzosa a través de las levas o la exigencia a las autoridades locales para proporcionar un contingente de sangre. Sin embargo, este procedimiento no debe de excluir en forma tajante la politización de la población local como el papel de los notables, de aquellos que tienen voz entre los labradores, para el enganche o al menos la obtención de alimentos y pertrechos. Algunos indicios sugieren que Barneond era negociante de aguardiente en la zona de Escuintla y la costa, así que tenía sus propias redes (amistades, socios, distribuidores, empleados y compañeros de armas) hacia esa zona para influir a favor del bando rebelde. Por ello, es primordial el testimonio de Rafael Muñoz, antiguo compañero del acusado en la facción ya que en el momento de ser cuestionado sobre quiénes podían confirmar el papel de Barneond dice "muchos de los mismos que están presos en la cárcel (...) así como también todos los vecinos de Escuintla y sus alrededores y demás pueblos de la costa." Esto hace comprensible el valor de castigar al acusado en uno de los principales teatros del conflicto, como Mataquescuintla, pues constituía uno de los enlaces entre la población local y los dirigentes Lucíos que ayudaba a mantener viva la rebelión.

El contexto en el que tuvo lugar la participación de Carlos Barneond en las partidas de rebeldes de los Lucíos es clave para entender con mayor precisión algunas de las posturas descritas en otras fuentes, pues se insertan en una lógica que diferenciaba a los bandos en pugna, en este caso los Lucíos anticarreristas y los liberales con sus programas y aquellos favorables a Carrera, según contextos de poder local pero conectados con las luchas de las elites a través de diversas mediaciones. Muchas de estas luchas se definían a partir de las percepciones sobre lo que se podían considerar las "injusticias", en un sentido amplio, aplicadas por los corregidores, comandantes y alcaldes favorables al gobierno durante la década de 1840. En este sentido los discursos liberales emitidos por las elites en la Ciudad de Guatemala o algunos líderes rebeldes eran reapropiados y reconstituidos según las relaciones de poder más concretas. Por ello, deben recuperarse las reflexiones sobre el "discurso oculto" reconstruido por aquellos que habían sido desplazados a nivel municipal y comunitario por los seguidores de Carrera en este mismo periodo. Estos excluidos de los puestos políticos y espacios de decisión pudieron expresar su descontento a partir del estallido de la rebelión en octubre de 1847, alimentando las filas rebeldes. Un detalle que no debe de olvidarse es que una parte considerable de los Lucíos tenían experiencia militar conseguida a partir de las guerras que estallaron con los Estados de Honduras y El Salvador a partir de 1826. Como ha sido rescatado por otras historiografías, la figura de los

\footnotetext{
${ }_{38}$ Otro testigo afirmó: "cuando el exponente estuvo a las órdenes del Comandante Sandoval, oyó hablar mucho de la actividad y buenos oficios que prestaba a la causa de los pueblos el inglés Barneon". AGCA, B Leg. 4314.
} 
cabecillas rebeldes representaba más a un programa que a un líder carismático. ${ }^{39}$ Para esto, repasaremos algunos de los elementos centrales en los programas hechos públicos por algunos líderes rebeldes y su relación con las tensiones a nivel local.

Para finales de 1848, las tropas rebeldes dirigidas por Vicente Cruz amenazaron a la Ciudad de Guatemala por el oriente. Se hicieron negociaciones con Vicente y su hermano Serapio Cruz, este último en Palencia. Con el intercambio entre autoridades y rebeldes, es posible conocer algunos puntos primordiales del programa que le sirvió a Cruz para movilizar a los pueblos y tropas. En la correspondencia intercambiada se puntualiza que el descontento hacia Rafael Carrera y su régimen estalló en 1847 por el maltrato que habían sufrido los pueblos de oriente, el peso militar sobre ellos, el abandono de Carrera del programa defendido en 1837-1839, la falta de "administración de justicia" y otra muchas más. La renuncia de Carrera en agosto de 1848 no bastó para detener la rebelión porque a pesar del cambio de gobierno, los funcionarios, muchos de ellos militares, se mantuvieron en sus puestos. Las tropas del gobierno arrasaron a las poblaciones de oriente, aumentando así el descontento. Por esto, Vicente Cruz consideraba como un elemento clave para la pacificación la indemnización por las pérdidas:

"Quedó en pie la cuestión sobre pérdidas y perjuicios causados por las tropas del gobierno y alguna vez por las de los Pueblos. Esa indemnización la juzga el que suscribe de estricta justicia, y además como un medio el más positivo de reconciliar a los habitantes de los pueblos con las autoridades constituidas. Convencido pues de la necesidad de que se indemnicen esas pérdidas, se ha consignado así como punto principal del arreglo." 40

El papel de la justicia, en sentido amplio, como eje para construir las bases políticas en el oriente respondía a la necesidad de atender los conflictos por tierras, impuestos, comercio y servicio militar. Es decir, el acceso a una instancia de decisión a la que pudieran avocarse e incidir. Por ello, uno de los puntos de la propuesta de Cruz hablaba de respetar el "derecho de petición" de los pueblos y particulares. El mismo Rafael Carrera sabía esto para $1840 .{ }^{41} \mathrm{Si}$ Cruz lograba materializar una parte importante de este programa, lograría mantener su propio liderazgo. En el convenio de Zacapa, alcanzado entre los representantes del gobierno y Vicente Cruz el 2 de febrero de 1849 se plasmaron varios puntos, pero los más importantes eran: la disponibilidad de 15.000 pesos para pagar los salarios de los soldados del Ejército de Cruz; 30.000 pesos para pagar las indemnizaciones a los habitantes de los pueblos, pero sin incluir a hacendados y propietarios; la distribución de ejidos a los pueblos que los solicitaran; los jueces de $1^{\mathrm{a}}$. Instancia no cobrarían costas; la garantía del derecho de petición para todos los habitantes; y no menos importante: el indulto a "todos los individuos del ejército que tengan causa o condena pendiente". Esta amnistía fue la que le permitió a Carlos Barneond regresar a la legalidad. ${ }^{42}$

\footnotetext{
${ }^{39}$ FRADKIN, Raúl La historia de una montonera: bandolerismo y caudillismo en Buenos Aires, 1826, Siglo XXI Editores, Buenos Aires, 2006.

${ }^{40}$ Foreign Office, Londres, FO, 254/2, fol. 307.

${ }^{41}$ El Tiempo, 21 de diciembre de 1840.

42 TOBAR CRUZ, Pedro Los Montañeses. La facción de los Lucíos, Editorial Universitaria, Guatemala, 1971, pp. 295-296.
} 
Aquí cabe una pregunta central ¿cómo había sido entendido por las poblaciones en el oriente este programa reivindicativo? Falta mucho todavía para llegar a comprender con mayor precisión el mosaico de tensiones y respuestas diferentes que habían marcado la experiencia de los pueblos y aldeas durante las primeras décadas de vida republicana en el oriente. Pero un ejemplo bastará para mostrar cómo este "programa" era reinterpretado a partir de las tensiones locales. El cura de San Luis Jilotepeque, pueblo con mayoría indígena, fue testigo de la ocupación realizada por una partida de Lucíos durante los primeros meses de 1848.

Los rebeldes se llamaban a sí mismos Tropas de Lucío, mostrando cómo la ejecución de este propietario en Palencia, origen de la rebelión, era un punto de identificación de todos los rebeldes en el oriente. Además, seguían las órdenes de Serapio Cruz, originario de Palencia. Durante la ocupación, los rebeldes, formados por indígenas del mismo pueblo, al grito de "muera todo ladino, viva la plebe libre, viva Lucío", atacaron a todos los ladinos. Entre enero y marzo de ese año, el cura reportó que habían muerto 23 ladinos como consecuencia de esta acción. Por ello, este concluía que "no sin fundamento, que la presente guerra es de razas, cuyos agentes me parecen son el asesinato y el robo (...) echaron a todos los ladinos en número de ciento cuarenta que vivían en el pueblo y en seguida incendiaron sus casas." ${ }^{43}$ Este caso sugiere la apropiación de los principios defendidos por los cabecillas rebeldes por parte de la población indígena de San Luis Jilotepeque en función de las rivalidades hacia la población ladina. Contradicción muy presente para la misma época también en Los Altos por el papel que los ladinos jugaban en la usurpación de tierras comunales, litigios, puestos en los gobiernos municipales y milicias. ${ }^{44}$ Atender estas contradicciones permitía a líderes de los rebeldes garantizarse apoyo, pertrechos, soldados y cierto nivel de obediencia por parte de los indígenas. No es extraño que una vez que Serapio y Vicente Cruz negociaron los tratados de febrero de 1849, la diversidad de muchos de sus seguidores haya provocado que no todos aceptasen dicho acuerdo y mantuvieran la lucha. El mismo caso de San Luis Jilotepeque expresa este resultado, pues desde la perspectiva de los indígenas rebeldes, el armisticio constituyó una derrota porque obligaba a aceptar el retorno de los ladinos perseguidos. Según el cura, luego de la firma del armisticio con los Cruz, él convocó a la Municipalidad y los Mayores a una misa de desagravio y una procesión "posteriormente me dediqué a calmar aquellos ánimos que se hallaban muy alterados y respirando con frecuencia deseos de venganza. Solo tenía que tratar a indígenas pues los ladinos no existía uno en el pueblo."

La historiografía del siglo XIX y la primera mitad del XX reconoció que el gobierno de El Salvador estuvo involucrado en la revuelta de los Lucíos, ya que les proporcionó a estos últimos armas, refugio, publicaciones y pertrechos en general. De ahí una parte de la explicación de la resistencia de la rebelión por casi cuatro años. Sin embargo, al analizar desde un plano social el conflicto, se observa cómo la politización de la población explica el apoyo mantenido por los pueblos a los distintos líderes rebeldes ya que ellos representaban un programa que podía ser leído según las contradicciones del régimen de Rafael Carrera durante su primera etapa (1840-1847) conectadas con los conflictos a nivel local,

\footnotetext{
${ }_{43}$ Archivo Histórico Arquidiocesano de Guatemala, AHA, Vicaría de Mita, 1844-1854, fol. 637638 y 644 . Cartas de fecha 21 de marzo y 5 de diciembre de 1848.

44 TARACENA, Arturo, Invención criolla..., cit.
} 
en marcos de lucha concreta. Claro, los rebeldes tenían sus fisuras, fragmentaciones y conflictos internos pero los unificaba el anticarrerismo.

La campaña para "pacificar" la región oriental, aplicada con el retorno de Rafael Carrera a partir de agosto de 1849, se articuló alrededor de tres ejes: movilización general de unidades militares, reasentamiento de la población dispersa en zonas bajo control y la acción misionera de curas para ayudar al proceso de reasentamiento. Cada uno de los ejes sustentaba al otro. Los reasentamientos, si bien forzosos también implicaron la repartición de tierras a los antiguos Lucíos, muchas veces a costa de algunos propietarios que habían padecido los ataques de los rebeldes. Recibir tierras en ese momento conllevó la obligación de prestar servicio militar en los cuerpos militares del Gobierno. Así, muchos Lucíos engrosaron las filas militares. Por su parte, la campaña misionera de curas en la región de la Montaña fue clave para afianzar todo el proceso de reasentamiento. No sin contradicciones, la colaboración de la Iglesia ayudó a que se alcanzaran los objetivos de concentrar a muchos habitantes en poblados. $^{45}$

A pesar de la derrota de los Lucíos entre 1849-1851, en el territorio quedó un problema preocupante para las autoridades: el bandolerismo. La presencia de bandas de asaltantes, cuatreros y ladrones había sido una constante en la región oriental por su condición de corredor comercial desde el siglo XVIII. Sin embargo, aquí se hace referencia a las partidas de antiguos militantes Lucíos que asaltaban en la región desde algunos parajes ocultos y otros desde El Salvador. Sin lugar a dudas constituyeron una preocupación para el Gobierno. Esto explica en parte la negativa de las autoridades para autorizar el retorno de una parte de la población reasentada a sus antiguas zonas de labores agrícolas ubicadas en las montañas pues podían servir de base social para estas bandas. ${ }^{46}$ En relación a los Lucíos exiliados en El Salvador, durante los últimos meses de 1850, conforme la campaña militar seguía su avance se tuvieron noticias de la derrota de partidas de rebeldes que, junto con sus familias, huyeron al Estado vecino. Muchos de ellos regresarían con los Ejércitos aliados para intentar derrocar a Rafael Carrera. ${ }^{47}$ Ellos fueron derrotados en la conocida Batalla de la Arada para inicios de 1851. Sin embargo, este problema se mantuvo conforme pasaron los años. En una fecha tardía como 1859, las autoridades fronterizas salvadoreñas recibieron la orden de internar a los exiliados guatemaltecos, identificados algunos como Lucíos, hacia los Departamentos de San Salvador, Cuscatlán, San Vicente y La Paz. ${ }^{48}$ De igual forma, la presencia de estos exiliados se hizo presente en los conflictos entre Guatemala y El Salvador, como se puede ver en 1863. Las tensiones provocadas por las diferencias políticas entre Carrera y Gerardo Barrios, la figura más conocida del liberalismo centroamericano para ese momento, desembocaron en la guerra que finalizó con la derrota de las fuerzas salvadoreñas para octubre del mismo año. Muchos liberales conocidos, como Manuel Yrungaray, yerno de Pedro Molina (antiguo militante liberal y periodista clave en el momento de la independencia en 1821), vivían refugiados bajo la protección de Barrios. Para el Salvador, uno de los

\footnotetext{
45 WOODWARD, Ralph Lee Rafael Carreras..., cit.; INGERSOLL, Hazel "The war of the Mountain. A study of reactionary peasant insurgency in Guatemala, 1837-1873", Tesis de Doctorado en Historia, George Washington University, 1972; SULLIVAN-GONZÁLEZ, Douglass Piety..., cit.; DARY, Claudia Unidos por nuestro territorio. Identidad y organización social en Santa María Xalapan, Editorial Universitaria, Guatemala, 2010.

${ }^{46}$ Hecho que llevó a conflictos por tierras durante las décadas de 1850 a 1870.

47 WOODWARD, Ralph Lee Rafael Carreras..., cit., pp. 317-346.

${ }^{48}$ Diario Oficial, 18 de mayo de 1859. Agradezco este dato a la Dra. Clara Pérez Fabregat.
} 
rebeldes más conocidos fue Santiago González, clave en la historia política de la década de 1860, pues durante la guerra se pronunció en contra del gobierno salvadoreño y alcanzó la presidencia por un periodo corto. Muchos de los antiguos Lucíos también combatieron a favor del Presidente Salvadoreño. Sin lugar a dudas, este grupo sería uno de los receptores de los exiliados guatemaltecos en 1870-1871, que encabezaron una columna militar desde oriente para derrocar al gobierno de Vicente Cerna en 1871 e iniciar el periodo del Liberalismo Cafetalero. ${ }^{49}$

Después de repasar periplo anterior, conviene retornar a Carlos Barneond y su caso. A partir de la discusión en la sección anterior, se puede observar una apropiación de cierta agenda anticarrerista pero reinterpretada según las tensiones y luchas locales, heterogénea y alimentada por algunos elementos del liberalismo promovida por algunas elites políticas. Esto hace posible, como hipótesis, que Barneond compartiera esta agenda, complementada por la inconformidad de algunos miembros de la comunidad francesa en Guatemala hacia Carrera, tanto por un rechazo político como por las exigencias de préstamos forzosos sobre estos comerciantes. Este último aspecto era visible en las disputas ventiladas públicamente en la Gaceta de Guatemala por las presiones diplomáticas francesas para conseguir una componenda con el gobierno desde 1844. En cuanto a la inclinación política, en sentido preciso, de Barneond hay algunos indicios que afirman esta situación. Como ya se mencionó, la vinculación hacia Vicente Cruz en 1848, la prisión sufrida en 1850 y el papel desempeñado como reclutador de rebeldes sugieren este hecho. Pero, a su vez, un testigo francés también lo sugiere. Alfred de Valois, diplomático, fue testigo de la labor del Cónsul para resolver el conflicto por el fusilamiento:

“El Sr. cónsul general Fourcade acudió al palacio y tuvo las mayores dificultades del mundo para persuadir al excelentísimo presidente [Rafael Carrera] de que no tenía el derecho de condenar a muerte a todas las personas que podían tener el mal gusto de no reconocerlo como un gran general, un gran político y un gran hombre, por decirlo en pocas palabras. El francés asesinado era, es cierto, un individuo bastante malvado; pero se tuvo que dar a entender al Sr. Carrera que no era lícito mandar fusilar a un villano sin juzgarlo, y sobre todo sin darle al representante de dicha persona las garantías de un juicio bueno y leal." 50

El mismo Alfred de Valois cambió su percepción de algunos rebeldes Lucíos frente a las experiencias que tuvo, por su acercamiento a Vicente Cruz en Zacapa. En una novela que Valois escribió con el seudónimo de Joseph Sue titulada Henri El Canciller: recuerdos de un viaje por América Central, ${ }^{51}$ se basó en la historia de Barneond pues el personaje principal, Henri, se involucró con los Lucíos cercanos a León Raymundo, a quien conoció en su periplo hacia la Ciudad de Guatemala. En la novela pudo discutir las razones del levantamiento contra el Gobierno. Pone en voz de Raymundo que un elemento clave fueron

\footnotetext{
${ }^{49}$ Las memorias de los actores en la coyuntura de 1867-1871 recuperan esta gesta. Una excelente síntesis a partir de la familia Samayoa es hecha en TORRES, Haroldo "La Familia Samayoa. Su vinculación al desarrollo capitalista en Guatemala en el siglo XIX (1830-1870)", Tesis de Licenciatura, Universidad de San Carlos de Guatemala, Guatemala, 2012.

${ }^{50}$ DE VALOIS, Alfred México, Havana y Guatemala. Notas de viaje, CEPHCIS-UNAM, México, 2015, pp. 303-304.

${ }^{51}$ DE VALOIS, Alfred Henri El Canciller: recuerdos de un viaje por América Central, CEPHCISUNAM, Mérida, 2013.
} 
las injusticias sufridas por él y su familia como el elemento para unirse a Carrera en 1837, pero como este no cumplió su promesa de justicia, dejó su bando y se unió a los rebeldes en 1847. Con respecto a los soldados que le siguen, Raymundo aclaró que son fieles a pesar de las duras condiciones durante la marcha (lo que indica una motivación más allá de la paga y el uso del pillaje como garantía de pago), algunos son ladinos y otros indios, pero que casi todos aprendieron a combatir por las luchas originadas desde de la independencia, es decir, por las múltiples formas de politización presentes durante la experiencia republicana.

A inicios de octubre de 1850 tuvo lugar el intercambio intenso de correspondencia entre el Cónsul Francés Fourcade y el Gobierno de Guatemala con el fin de evitar el fusilamiento de Carlos Barneond. El 6 de octubre circuló el rumor que varios prisioneros habían sido extraídos de la cárcel militar en Guatemala para ser llevados a Mataquescuintla. Uno de ellos era Carlos Barneond. Ante el riesgo de su fusilamiento, el Cónsul se comunicó el 7 con el Ministro de Gobierno para solicitar explicaciones a estos rumores. Ese mismo día, el Ministro contestó al diplomático francés para notificarle que se había comunicado en forma inmediata la orden a las autoridades militares para evitar el fusilamiento. En la misma fecha, el Comandante General, Rafael Carrera, respondió informando que un mensajero había sido enviado a Mataquescuintla con la orden dada por el Ministro. Poco después se notificó al Cónsul Francés y al Ministro de Hacienda que "las órdenes convenientes para evitar el hecho llegaron a Mataquescuintla después de haberse consumado."

El fusilamiento de un ciudadano francés abrió un nuevo capítulo en las disputas entre el Gobierno y el representante francés, marcadas por las quejas de comerciantes de esa nacionalidad por las exigencias de préstamos forzosos, incautaciones y otros problemas semejantes durante las guerras que asolaron a Guatemala. Sin ocultar el hecho de las inclinaciones políticas de algunos de ellos a favor de los partidarios anticarreristas. A esto se agregó la solicitud de protección de varios "ciudadanos españoles" al Cónsul Francés para evitar nuevos préstamos forzosos. Ante la inexistencia de relaciones diplomáticas entre España y Guatemala para el periodo 1847-1851, el diplomático francés de turno tuvo a su cargo las gestiones de los asuntos de estos españoles. Sin embargo, el conflicto creció con la autorización del Cónsul para atender las solicitudes de estos "españoles". El debate corrió por el hecho que muchos de estos "españoles" eran en realidad ciudadanos y comerciantes guatemaltecos pero que acudieron a esta figura para salvar su peculio. En algunos casos, los solicitantes habían desempeñado distintos puestos políticos en la Municipalidad, Consulado de Comercio, Cuerpo Legislativos y otros. Con estos antecedentes, la suma de un caso grave como el fusilamiento de Barneond agudizaron las diferencias entre el gobierno y el Cónsul. ${ }^{52}$ Como parte del arreglo de las disputas por pérdidas, el caso Barneond concluyó con el pago de 1.500 pesos a la madre y otra cantidad semejante como dote para la hija. El cierre diplomático se hizo con la firma del tratado de 1854 entre el representante de Guatemala en París y el gobierno francés. ${ }^{53}$

\footnotetext{
${ }^{52}$ Una visión general se puede ver en SCHOONOVER, Thomas The French in Central America. Culture and commerce, 1820-1930, Rowman \& Littlefield Publishers, 1999, pp. 27-29. Estas disputas también representaban una tensión con la preeminencia que disfrutaba F. Chatfield, cónsul inglés en Guatemala.

${ }^{53}$ Archive du Ministère des Affaires Étrangères de France (AMAEF), Contentieux, 181. Aquí aparece el expediente sobre las negociaciones para el fin de las quejas de los comerciantes franceses y el tratado de 1854. Entre la correspondencia se cita una carpeta con el caso
} 


\section{Conclusiones}

Después de la revisión de algunos pocos casos, el panorama que empieza a dibujarse sobre la justicia y las implicaciones políticas deja claro otra dimensión de la vida militarizada de la época: los espacios profundos de negociación para la conservación de las unidades militares y milicianas. Si bien es cierto que el nuevo orden político en la década de 1850 sentó las bases para un Estado más centralizado, la forma en que se alcanzó ese objetivo siguió caminos complejos. En este sentido, este artículo buscó indagar uno de estos caminos: el de la justicia y su relación con los militares. Falta todavía explorar parte de los archivos judiciales guatemaltecos a pesar de las pérdidas de material, sobre todo el proveniente del Ejército mismo. Sin embargo, se puede observar el potencial que el fondo documental disponible tiene.

Los casos discutidos muestran varios aspectos centrales que deben de ser examinados con mayor detenimiento para entender la dinámica política de mediados de siglo XIX. El primero es profundizar el análisis de la administración de la justicia en la construcción de la legitimidad republicana. ${ }^{54}$ En el caso guatemalteco, esta relación implica conocer el verdadero sentido de justicia, nuevo y antiguo, con respecto a la población maya, pues ellos articularon la centralización política de Rafael Carrera y la región de Los Altos. Por otro lado, el papel político de los que hablan en nombre de la justicia: jueces, fiscales, regentes y alcaldes. ${ }^{55} \mathrm{Y}$, en el caso de los militares, hacer el balance territorial de la aplicación de estos principios del fuero militar, la negociación con las milicias locales y la conservación de la alianza a través del día a día en los juzgados y en la autonomía garantizada a las unidades militares locales. Para el caso de Chiapas, a pesar de las carencias documentales, se puede rescatar con la centralidad de los militares en distintos momentos, un trabajo que ganará mucho con la nueva generación de investigadores cuyos temas no se encuentran limitados a la perspectiva nacional y que están revestidos de un carácter colaborativo, un hecho que sin lugar a dudas hubiera agradado al querido maestro Juan Carlos Garavaglia y con el que se habría sentido más que satisfecho.

\footnotetext{
Barneond, pero no fue posible localizarla.

${ }^{54}$ Es una de las ideas centrales en CASELLI, Elisa (Coord.) Justicias, agentes y jurisdicciones..., cit.

${ }^{55}$ CONNAUGHTON, Brian "El fiscal de la Suprema Corte...", cit.
} 